\title{
Molecular typing and in vitro antifungal susceptibility of Cryptococcus spp from patients in Midwest Brazil
}

\author{
Olivia Cometti Favalessa ${ }^{1}$, Daphine Ariadne Jesus de Paula ${ }^{3}$, Valéria Dutra ${ }^{3}$, Luciano Nakazato ${ }^{3}$, \\ Tomoko Tadano ${ }^{2}$, Márcia dos Santos Lazera ${ }^{4}$, Bodo Wanke ${ }^{4}$, Luciana Trilles ${ }^{4}$, Maria Walderez Szeszs ${ }^{5}$, \\ Dayane Silva ${ }^{5}$, Rosane Christine Hahn ${ }^{1,2}$ \\ ${ }^{1}$ Laboratório de Micologia, Faculdade de Medicina, Universidade Federal de Mato Grosso, Cuiabá, MT, Brazil \\ ${ }^{2}$ Hospital Universitário Júlio Müller, Universidade Federal de Mato Grosso, Cuiabá, MT, Brazil \\ ${ }^{3}$ Laboratório de Microbiologia e Biologia Molecular Veterinária, Universidade Federal de Mato Grosso, Cuiabá, MT, \\ Brazil \\ ${ }^{4}$ IPEC - Laboratório de Micologia - FIOCRUZ, Rio de Janeiro, RJ, Brazil \\ ${ }^{5}$ IAL - Instituto Adolfo Lutz - Seção de Micologia São Paulo, SP, Brazil.
}

\begin{abstract}
Introduction: Cryptococcosis is a systemic fungal infection that affects humans and animals, mainly due to Cryptococcus neoformans and Cryptococcus gattii. Following the epidemic of acquired immunodeficiency syndrome (AIDS), fungal infections by $C$. neoformans have become more common among immunocompromised patients. Cryptococcus gattii has primarily been isolated as a primary pathogen in healthy hosts and occurs endemically in northern and northeastern Brazil. We to perform genotypic characterization and determine the in vitro susceptibility profile to antifungal drugs of the Cryptococcus species complex isolated from HIV-positive and HIV-negative patients attended at university hospitals in Cuiabá, MT, in the Midwestern region of Brazil.

Methodology: Micromorphological features, chemotyping with canavanine-glycine-bromothymol blue (CGB) agar and genotyping by URA5-RFLP were used to identify the species. The antifungal drugs tested were amphotericin $\mathrm{B}$, fluconazole, flucytosine, itraconazole and voriconazole. Minimum inhibitory concentrations (MICs) were determined according to the CLSI methodology M27-A3.

Results: Analysis of samples yelded C. neoformans AFLP1/VNI (17/27, 63.0\%) and C. gattii AFLP6/VGII (10/27, 37.0\%). The MICs ranges for the antifungal drugs were: amphotericin B (0.5-1 mg/L), fluconazole (1-16 mg/L), flucytosine (1-16 mg/L), itraconazole (0.25-0.12 mg/L) and voriconazole $(0.06-0.5 \mathrm{mg} / \mathrm{L})$. Isolates of $C$. neoformans AFLP1/VNI were predominant in patients with HIV/AIDS, and $C$. gattii VGII in HIV-negative patients. The genotypes identified were susceptible to the antifungal drugs tested.

Conclusion: It is worth emphasizing that AFLP6/VGII is a predominant genotype affecting HIV-negative individuals in Cuiabá. These findings serve as a guide concerning the molecular epidemiology of C. neoformans and C. gattii in the State of Mato Grosso.
\end{abstract}

Key words: Cryptococosis; Cryptococcus complex; antifungal drugs.

J Infect Dev Ctries 2014; 8(8):1037-1043. doi:10.3855/jidc.4446

(Received 22 November 2013 - Accepted 15 February 2014)

Copyright $(2014$ Favalessa et al. This is an open-access article distributed under the Creative Commons Attribution License, which permits unrestricted use, distribution, and reproduction in any medium, provided the original work is properly cited.

\section{Introduction}

Cryptococcosis is a severe systemic fungal infection affecting humans and a variety of animals. It is mainly caused by two species of yeasts of the genus Cryptococcus: Cryptococcus neoformans (serotypes A, D and AD) and Cryptococcus gattii (serotype B and C) [1]. Regarding molecular types, $C$. neoformans has been grouped into AFLP1/VNI and AFLP1A/VNII (serotype A), AFLP3/VNIII (serotype AD) and AFLP2/VNIV (serotype D), whereas $C$. gattii has been grouped into types AFLP1/VGI, AFLP6/VGII, AFLP5/VGIII and AFLP7/AFLP10/VGIV (serotypes $\mathrm{B}$ and $\mathrm{C})$ [2]. Immunocompromised patients are more frequently affected by $C$. neoformans serotypes A and D. [3-5]

This species is distributed worldwide and is considered an important cause of morbidity and mortality in immunocompromised individuals and particularly among HIV-infected patients [3-5]. C. neoformans is associated with organic matter in the habitats of pigeons, birds in captivity and domestic environments, in domestic dust and decomposing wood and in different species of hollow trees [6-8].

Until recently, it was believed that the species $C$. gattii was confined to regions with tropical and subtropical climates, like Australia and New Zealand, where it is associated with species of Eucalyptus spp. 
However, it was described in a recent outbreak on Vancouver Island, Canada, a temperate region, suggesting that the species $C$. gattii has adapted to different environmental conditions [9]. It has also been isolated from clinical specimens in several other areas of the world, including Mexico, parts of Latin America, Europe, Southern California, Hawaii, India and Africa [10-15].

In Brazil, cryptococcosis caused by $C$. neoformans occurs in all regions of the country [5,16-20]. However, $C$. gattii has emerged as a primary pathogen infecting immunocompetent individuals, particularly children, adolescents and young adults in northeastern Brazil, where cryptococcosis is characterized by high mortality rates [18,20-22].

Infection is caused by the inhalation of viable propagules of these yeasts directly from the environment. After invading the lung tissue, hematogenous dissemination occurs with a predisposition for the central nervous system [23]. Meningitis and meningoencephalitis are the most common clinical manifestations in cases of cryptococcal meningitis caused by Cryptococcus spp, while $C$. gattii shows a propensity to cause cryptococcomas, focal CNS lesions and important neurological sequelae $[14,15,23,24]$.

The purpose of this study was to characterize the Cryptococcus species complex and its molecular types derived from clinical isolates obtained from patients diagnosed with cryptococcosis admitted to the university hospitals of Cuiabá, MT, using chemotyping in canavanine-glycine-bromothymol blue medium, genotypic characterization by $\mathrm{PCR}$ and URA5-RFLP. The in vitro susceptibility profiles of $C$. neoformans and C. gattii to amphotericin B, fluconazole, flucytosine, itraconazole and voriconazole. were also determined.

\section{Methodology}

\section{Cryptococcus identification}

Between August 2010 and July 2013, clinical isolates of Cryptococcus spp from patients admitted to the university hospitals of Cuiabá (General University Hospital, HGU; Julio Muller University Hospital, HUJM), were identified in the Mycology Research Laboratory of the Federal University of Mato Grosso (UFMT). Identification was achieved by: visualizing micromorphological features in direct examination with India ink; biochemical tests, phenol oxidase positive on Niger seed agar and urease positive; and phenotypic characterization by chemotyping on canavanine-glycine-bromothymol blue (CGB) medium.

\section{Genotypic characterization}

Genotypic identification was performed by polymerase chain reaction (PCR) using paired primers CNB49A (5'ATTGCGTCCATCCAACCGTTATC-3 ') and CNB49S (5'ATTGCGTCCAAGTGTTGTTG-3'), specific for $C$. gattii and CNA70S: (5 'ATT GCG GAG CTC TCCACCAAG 3') and CNA70A (5 'ATT GCG TCC ATG TTA CGTGGC 3') specific for $C$. neoformans $[25,26]$.

\section{DNA extraction}

For DNA extraction, the protocol described by Del Poeta et al (1999) [27] was used with modifications. Lysis buffer (0.5 mM EDTA pH 8.0, $100 \mathrm{mM} \mathrm{NaCl}$, $10 \mathrm{mM}$ Tris $\mathrm{pH} 8.00$, and $0.5 \%$ SDS) was used, with $0.05 \mathrm{~g}$ of glass beads. The tubes were initially agitated in a vortex for 5 minutes, then boiled at $100^{\circ} \mathrm{C}$ for 5 minutes and finally, centrifuged at $16,000 \mathrm{~g}$ for 5 minutes. The aqueous phase was extracted with 0.5 volume of buffered phenol and chloroform, shaken gently for 5 minutes. This was then centrifuged $(6,000$ $g$ for 10 minutes) and the nucleic acid content present in the upper phase was collected and precipitated in the presence of $0.2 \mathrm{M} \mathrm{NaCl}, \mathrm{pH} 5.2$, and $1 \mathrm{~mL}$ isopropanol for 16 hours at $-20^{\circ} \mathrm{C}$, and then centrifuged $(10,000 \mathrm{~g}$ for 10 minutes), washed with 1 $\mathrm{mL}$ of $70 \%$ ethanol and dried. Incubation was performed overnight at $-20^{\circ} \mathrm{C}$ to achieve precipitation. The DNA was collected by centrifugation at $16,000 \mathrm{~g}$ for 5 minutes, after which the supernatant was discarded. The pellet was washed with $1 \mathrm{~mL}$ of cold $70 \%$ ethanol and resuspended in $0,05 \mathrm{~mL}$ of MilliQ water. Subsequently, the DNA was treated with RNAse A for 1 hour at $37^{\circ} \mathrm{C}$. The quality and integrity of the DNA was analyzed by electrophoresis in $1.0 \%$ agarose gel at $100 \mathrm{~V}$ per $\mathrm{cm}$ with the aid of a transilluminator (Loccus, São Paulo, Brazil).

\section{Molecular typing}

Twenty-seven Brazilian clinical isolates were typed by URA5-RFLP and PCR-fingerprinting using the minisatellite-specific core sequence of the wildtype phage M13. PCR of the gene URA5was performed in a final volume of $50 \mu \mathrm{L}$. Each reaction contained $50 \mathrm{ng}$ of DNA, 1x PCR buffer [160 mM $\left(\mathrm{NH}_{4}\right)_{2} \mathrm{SO}_{4}, 670 \mathrm{mM}$ Tris-HCI $\left(\mathrm{pH} 8.8\right.$ at $\left.25^{\circ} \mathrm{C}\right), 0.1 \%$ Tween-20 - (Bioline Inc., Taunton, USA), $0.2 \mathrm{mM}$ each of dATP, dCTP, dGTP, and dTTP (Roche Diagnostics GmbH, Mannheim, Germany), $3 \mathrm{mM}$ 
magnesium chloride, $1.5 \mathrm{U}$ BioTaq DNA polymerase (Bioline Inc., Taunton, USA), and 50 ng of each URA5 primer (5' ATGTCCTCCCAAGCCCTCGACTCCG 3') and SJ01 (5' TTAAGACCTCTGAACACCGTACTC 3') [28]. PCR was performed for 35 cycles in a Perkin-Elmer thermal cycler (model 480 ) at $94^{\circ} \mathrm{C}$ with 2 minutes initial denaturation, $45 \mathrm{~s}$ denaturation at $94^{\circ} \mathrm{C}, 1$ minute annealing at $61^{\circ} \mathrm{C}, 2$ minutes extension at $72^{\circ} \mathrm{C}$, and final extension cycle for 10 minutes at $72^{\circ} \mathrm{C}$. A total of $30 \mu \mathrm{l}$ of PCR products were double digested with Sau96I (10 U/ $\mu \mathrm{L})$ and HhaI $(20 \mathrm{U} / \mu \mathrm{L})$ for 3 hours, and the fragments were separated by $3 \%$ agarose gel electrophoresis at $100 \mathrm{~V}$. RFLP patterns were assigned visually by comparison with patterns obtained from standard strains provided by the Mycology laboratory of the Institute of Clinical Research Evandro Chagas Oswaldo Cruz Foundation and included WM 148 (VNI), WM 626 (VNII), WM 628 (VNII), 629 (VNIV), WM 179 (VGI), WM 178 (VGII), WM 161 (VGIII) and WM 779 (VGIV).

\section{Antifungal susceptibility testing}

The in vitro susceptibility profiles of $C$. neoformans and $C$. gattii against antifungal agents were determined by using the reference method of broth microdilution, in accordance with document M27-A3 of the CLSI. Cutoff points for C. neoformans and $C$. gattii have not been established by the CLSI, so those described by CLSI document M27-A3 for Candida spp were used, as previously reported [30-
33]. The antifungal drugs tested were amphotericin $B$, fluconazole, flucytosine, itraconazole and voriconazole.

\section{Results}

Among the 27 patients diagnosed with cryptococcosis during the study period, 27 strains of Cryptococcus spp were isolated. Fourteen patients were HIV-positive, with 13 presenting isolates of $C$. neoformans VNI and one of $C$. gattii VGII. Thirteen patients showed HIV negative serology, of which 10 presented isolates of $C$. gattii and three of $C$. neoformans. Fifteen of the 27 infected individuals were male, with ages ranging from 6 to 73 years (mean age, 37.9 years).

Cryptococcus neoformans was the most prevalent isolate among HIV-infected individuals and C. gattii was the most prevalent among HIV-negative individuals. The antifungal drug susceptibility tests showed in vitro activity against isolates of Cryptococcus spp and the MICs ranges to $C$. neoformans were: amphotericin B $0.5-1 \mathrm{mg} / \mathrm{L}$; fluconazole $1-16 \mathrm{mg} / \mathrm{L}$; flucytosine $0.5-8 \mathrm{mg} / \mathrm{L}$; itraconazole $0.03-0.25 \mathrm{mg} / \mathrm{L}$ and voriconazole 0.06 $0.5 \mathrm{mg} / \mathrm{L}$ MICs ranges against $C$. gattii were: amphotericin B $0.5-1 \mathrm{mg} / \mathrm{L}$; fluconazole $1-16$ $\mathrm{mg} / \mathrm{L}$; flucytosine $1-16 \mathrm{mg} / \mathrm{L}$; itraconazole $0.03-0.5$ $\mathrm{mg} / \mathrm{L}$ and voriconazole $0.06-0.5 \mathrm{mg} / \mathrm{L}$. The minimum inhibitory concentrations (MICs) and $\mathrm{MIC}_{50}$ and $\mathrm{MIC}_{90}$ values are presented in Table 1.

Table 1. In vitro susceptibility of the genotypes of Cryptococcus spp to fluconazole, itraconazole, voriconazole, flucytosine and amphotericin B in isolates from HIV-positive and HIV-negative patients.

\begin{tabular}{lcccc}
\hline \multirow{2}{*}{ Genotype and antifungal drug } & MIC range & ${ }^{*} \mathbf{M I C}_{\mathbf{5 0}}$ & ${ }^{*} \mathbf{M I C}_{\mathbf{9 0}}$ & ${ }^{* *} \mathbf{G M}$ \\
\cline { 2 - 5 } $\boldsymbol{C .}$ neoformans VNI (n= 17) & $(\mathrm{mg} / \mathrm{L})$ & $(\mathrm{mg} / \mathrm{L})$ & $(\mathrm{mg} / \mathrm{L})$ & $(\mathrm{mg} / \mathrm{L})$ \\
Amphotericin B & & & & \\
Fluconazole & $0.5-1$ & 0.5 & 1 & 0.67 \\
Flucytosine & $1-16$ & 4 & 8 & 4.34 \\
Itraconazole & $0.5-8$ & 4 & 4 & 2.77 \\
Voriconazole & $0.03-0.25$ & 0.12 & 0.25 & 0.09 \\
C. gattii VGII (n= 10) & $0.06-0.5$ & 0.5 & 0.5 & 0.28 \\
Amphotericin B & & & & 0.71 \\
Fluconazole & $0.5-1$ & 0.5 & 1 & 7.46 \\
Flucytosine & $1-16$ & 8 & 16 & 4.92 \\
Itraconazole & $1-16$ & 8 & 8 & 0.22 \\
Voriconazole & $0.03-0.5$ & 0.25 & 0.5 & 0.28 \\
\hline
\end{tabular}

* MIC50 and MIC 90 , the concentration capable of inhibiting the growth of isolates by $50 \%$ and $90 \%$, respectively. ** GM: geometric means. 


\section{Discussion}

Epidemiological studies addressing the molecular features of species belonging to the genus Cryptococcus have been conducted extensively in numerous parts of the world [2,34-36]. However, in Brazil, molecular epidemiology studies are still required to elucidate the distribution of molecular types in all five Brazilian regions. Despite this, the few epidemiological studies conducted in Brazil have demonstrated differences in the distribution of the genotypes of these species in these regions [17-21,36]. In Mato Grosso, this is the first report describing the molecular types circulating in the state capital of Cuiabá. This study demonstrated the prevalence of cryptococcal meningitis by $C$. neoformans VNI among HIV-infected patients and C. gattii VGII in patients presenting negative serology for HIV.

Cryptococcosis has become more frequently diagnosed among HIV/AIDS patients and is considered an important cause of morbidity and mortality. C. neoformans is the species with the largest number of isolates among species belonging to the Cryptococcus complex [5,16-18,37]. Currently, an increasing number of cases of cryptococcosis have been reported in patients without HIV. Regarding this finding, we recommend testing for $C$. gattii as a primary pathogen, since it affects apparently healthy individuals, especially in northern and northeastern Brazil [21,22,36].

In Brazil, $C$. neoformans predominates in clinical isolates from HIV/AIDS patients, particularly in the southern, southeastern and mid-western regions [9,16$18,20]$. Of the $C$. neoformans species analyzed in this study, all showed the molecular type VNI, a prevalence observed by other researchers $[8,10,19,20]$. In the 1990s, during the outbreak that occurred on Vancouver Island and nearby areas in Canada and the USA, the genotype $C$. gattii VGIIa / VGIIc emerged as a primary pathogen, illustrating that the species is not only present in tropical and subtropical regions, but also in other geographic areas, including those with temperate climates. This outbreak indicated that exposure to environmental sources, such as trees and soil contaminated by this yeast, can lead to cryptococcosis infection in humans and animals $[38,39,40]$. In a study analyzing environmental samples in Cuiabá, MT, Anzai et al. [41] also isolated the genotype $C$. gattii VGII, which is similar to that detected in the clinical isolates analyzed in this work.

Santos et al. [21] studied 43 cases of meningitis caused by Cryptococcus spp, in which C. gattii was the most common isolate among HIV-negative patients $(19 / 29 ; 65.5 \%)$. The genotype VGII $(25 / 56$, $44.6 \%$ ) was the most frequently isolated, as reported previously [36-42], and in agreement with this work. Different results have been observed in southern Brazil, with Casali et al. [18] reporting 11 isolates of C. gattii serotype B type VGIII among the clinical samples they studied. In Goiânia, MS, Souza et al. [20] identified C. gattii serotype B type VGIII in four clinical samples.

In vitro susceptibility tests are not routinely performed in Brazilian laboratories, particularly in the public health services, even though these tests are extremely useful for selecting the appropriate therapy. In this study, clinical isolates of $C$. neoformans and $C$. gattii were susceptible to the antifungal agents tested (Table 1).

Studies conducted in several parts of the world have shown low $\mathrm{MIC}_{50}$ and $\mathrm{MIC}_{90}$ values for fluconazole against $C$. neoformans VNI [43-45]. In this study, the $\mathrm{MIC}_{50}$ and $\mathrm{MIC}_{90}$ values for fluconazole were 4-8 $\mathrm{mg} / \mathrm{L}$; however, higher values $(2-128 \mathrm{mg} / \mathrm{L})$ have been reported for isolates of $C$. neoformans VNI [46].

High MIC values ( $\geq 64 \mathrm{mg} / \mathrm{L}$ ) have been reported for fluconazole against $C$. gattii [44,47], in contrast to this study, which determined values $\leq 16 \mathrm{mg} / \mathrm{L}$. Hagen et al. [48] analyzed 350 isolates of $C$. gattii originating from clinical, environmental and animal sources and reported that MIC values for flucytosine and fluconazole were higher, i.e. these antifungal drugs showed less activity in vitro against $C$. gattii compared with isavuconazole, itraconazole, posaconazole, and voriconazole. Regarding new azoles, voriconazole demonstrated strong activity against the genotypes, even against isolates that presented diminished susceptibility to fluconazole. In this study, voriconazole also showed low MIC values against $C$. gattii and C. neoformans, suggesting that voriconazole could be an important drug for the treatment of cryptococcosis in cases of resistance to fluconazole, and due to the toxic effects related to amphotericin B. Despite the promising in vitro results obtained for voriconazole, numerous other studies are required to determine the correlation between in vitro susceptibility and therapeutic success in vivo.

Following their analysis of susceptibility profiles of C. gattii genotypes, Chong et al. [49] reported higher MIC values for fluconazole $(\geq 64 \mu \mathrm{g} / \mathrm{mL}$ ) against $C$. gattii VGII than against $C$. gattii VGIII and VGI [48]. Iqbal et al. [50] reported differences in the susceptibility profiles of the molecular types of $C$. gattii, having determined higher MIC values for the 
VGII subtypes than the VGI and VGIII subtypes. In Brazil, Souza et al. [20] reported low MIC values for voriconazole and amphotericin B against isolates of $C$. gattii. It is worth highlighting that $C$. gattii VGIII was identified in this study and that the MIC values obtained for amphotericin B were low, in agreement with those in the literature [47,50,51], considering the cutoffs used by Nguyen and $\mathrm{Yu}$ [30] and Lozano-Chui et al. [31]. For voriconazole, MIC values against $C$. gattii $($ range $=0.06-0.5 \mathrm{mg} / \mathrm{L}$ were in agreement with those presented by Espinel-Ingroff et al [53], whereas against $C$. neoformans $\mathrm{MIC}$ values (range $=0.06-0.5$ $\mathrm{mg} / \mathrm{L}$ ), were lower compared with those of the same study.

The majority of studies addressing in vitro susceptibility testing for amphotericin $\mathrm{B}$ against $C$. neoformans and $C$. gattii have shown that many of these isolates are susceptible at MIC values $\leq 1 \mathrm{mg} / \mathrm{L}$ $[47,48,50-53]$, similar to the MIC values obtained in this work. However, the literature reports MIC values for amphotericin $\mathrm{B} \geq 1 \mu \mathrm{g} / \mathrm{mL}$, such as Lozano-Chui et al. [31], who reported MIC values of 3-4 mg/L, which were associated with treatment failure.

Given the severity of infection by Cryptococcus gattii and the potential neurological sequelae that affect not only immunocompromised, but also healthy individuals, the adequation of laboratory facilities to provide early diagnosis of cryptococcosis in Brazil is essential. Moreover, the importance of performing molecular typing of the species of $C$. gattii should be emphasized, given literature findings indicating the existence of differences in the in vitro susceptibility profiles. Understanding the molecular types circulating in different Brazilian regions and their correlation with the minimal inhibitory concentrations values obtained for the antifungals most frequently used in medical practice should elucidate aspects of this important enigmatic puzzle, the Cryptococcus complex.

\section{References}

1. Kwon-Chung KJ, Varma SA (2006) Do major species concepts support one, two or more species within Cryptococcus neoformans? FEMS Yeast Res 6: 574-587.

2. Meyer W, Aanensen DM, Boekhout T, Cogliati M, Diaz MR, Esposto MC, Fisher M, Gilgado F, Hagen F, Kaocharoen S, Litvintseva AP, Mitchell TG, Simwami SP, Trilles L, Viviani MA, Kwon-Chung J (2009) Consensus multi-locus sequence typing scheme for Cryptococcus neoformans and Cryptococcus gattii. Med Mycol 47: 561-570.

3. Perfect JR, Dismukes WE, Dromer F, Goldman DL, Graybill JR, Hamill RJ, Harrison TS, Larsen RA, Lortholary O, Nguyen MH, Pappas PG, Powderly WG, Singh N, Sobel JD, Sorrell TC (2010) Clinical practice guidelines for the management of cryptococcal disease: 2010 update by the infectious diseases society of america. Clin Infect Dis 50: 291-322.

4. Sajadi MM, Roddy KM, Chan-Tack KM, and Forrest GN (2009) Risk factors for mortality from primary cryptococcosis in patients with HIV. Postgrad Med 121: 107-113.

5. Fernandes OFL, Costa TR, Costa MR, Soares AJ, Pereira AJSC, Silva MR (2000) Cryptococcus neoformans isolados de pacientes com AIDS. Rev Soc Bras Med Trop 33: 75-78.

6. Nishikawa MM, Lazera MS, Barbosa GG, Trilles L, Balassiano BR, Macedo RC, Bezerra CC, Pérez MA, Cardarelli P, Wanke B (2003) Serotyping of 467 Cryptococcus neoformans isolates from clinical and environmental sources in Brazil: analysis of host and regional patterns. J Clin Microbiol 41: 73-77.

7. Lin X, Heitman J (2006) The biology of the Cryptococcus neoformans species complex. Annu Rev Microbiol 60: 69105.

8. Passoni LFC, Wanke B, Nishikawa MM, Lazera MS (1998) Cryptococcus neoformans isolated from human dwellings in Rio de Janeiro,Brazil: an analysis of the domestic environment of AIDS patients with and without cryptococcosis. Med Mycol 36: 305-311.

9. Kidd SE, Hagen F, Tscharke RL, Huynh M, Bartlett KH, Fyfe M, MacDougall L, Boekhout T, Kwon-Chung KJ, Meyer W (2004) A rare genotype of Cryptococcus gattii caused the cryptococcosis outbreak on Vancouver Island (British Columbia, Canada). Proc Natl Acad Sci U S A 101:1725817263.

10. Murthy JMK (2007) Fungal infections of the central nervous system: The clinical syndromes. Neurol India 55: 221-225.

11. Chen S, Sorrel Tl, Nimmo G,Speed B, Currie B, Ellis D, Marriott D, Pfeiffer T, Parr D, and Byth K (2000) Epidemiology and host- and variety dependent characteristics of infection due to Cryptococcus neoformans in Australia and New Zealand. Australasian Cryptococcal Study Group. Clin Infect Dis 31: 499-508.

12. Morgan J, McCarthy KM, Gould S, Fan K, ArthingtonSkaggs B, Iqbal N,Stamey K, Hajjeh RA, Brandt ME, and the Gauteng (2006) Cryptococcal Surveillance Initiative Group. Cryptococcus gattii infection: characteristics and epidemiology of cases identified in a South African province with high HIV seroprevalence, 2002-2004. Clin Infect Dis 43: 1077-1080.

13. Jain NBL, Wickes BL, Keller SM, Fu J, Casadevall A, Jain P, Ragan MA, Banerjee U, Fries BC (2005) Molecular epidemiology of clinical Cryptococcus neoformans strains from India. J Clin Microbiol 43: 5733-5742.

14. Meyer W and Trilles L. Genotyping of the Cryptococcus neoformans/Cryptococcus gattii Species Complex. Australian Biochemist 2010 (41); 12-15.

15. Hagen F, Colom MF, Swinne D, Tintelnot $\mathrm{K}$, Iatta $\mathrm{R}$, Montagna MT, Torres-Rodriguez JM, Cogliati M, Velegraki A, Burggraaf A, Kamermans A, Sweere JM, Meis JF, Klaassen CH, Boekhout T (2012) Autochthonous and dormant Cryptococcus gattii infections in Europe. Emerg Infect Dis. 18: 1618-16124.

16. Favalessa OC, Ribeiro LC, Tadano T, Fontes CJF, Dias FB, Coelho BPA, Hahn RC (2009) Primeira descrição da caracterização fenotípica e susceptibilidade in vitro a drogas de leveduras do gênero Cryptococcus spp isoladas de pacientes HIV positivos e negativos, Estado de Mato Grosso. Rev Soc Bras Med Trop 42: 661-665. 
17. Matsumoto MT, Fusco-Almeida AM, Baeza LC, Melhem MSC, Mendes-Giannini MJS (2007) Genotyping, serotyping and determination of mating-type of cryptococcus neoformans clinical isolates from São Paulo State, Brazil. Rev Inst Med Trop S Paulo 49: 41-47.

18. Casali AK, Goulart L, Rosa e Silva LK, Ribeiro AM, Amaral AA, Alves SH, Schrank A, Meyer W, Vainstein MH (2003) Molecular typing of clinical and environmental Cryptococcus neoformans isolates in the Brazilian state Rio Grande do Sul. FEMS Yeast Res 3: 405-415.

19. Matos CS, Andrade NS, Oliveira NS, Barros TF (2012) Microbiological characteristics of clinical isolates of cryptococcus spp in Bahia, Brazil: Molecular Types and antifungal susceptibilities. Eur J Clin Microbiol Infect 31: $1647-1652$.

20. Souza LKH, Souza-Junior AH, Costa CR, Fagnello J, Vainstein MH, Chagas ALB, Souza ACM, Silva MRR (2009) Molecular typing and antifungal susceptibility of clinical and environmental Cryptococcus neoformans species complex isolates in Goiania, Brazil. Mycoses 53: 62-67.

21. Santos WRA, Meyer W, Wanke B, Costa SPSE, Trilles L, Nascimento JLM, Medeiros R, Morales BP, Bezerra Cde C, Macêdo RC, Ferreira SO, Barbosa GG, Perez MA, Nishikawa MM, Lazéra Mdos S (2008) Primary endemic Cryptococcosis gattii by molecular type VGII in the state of Pará, Brazil. Mem Inst Oswaldo Cruz 103: 813-818.

22. Correa MP, Oliveira EC, Duarte RR, Pardal PP, Oliveira FM, Severo LC (1999) Cryptococcosis in children in the state of Pará, Brazil. Rev Soc Bras Med Trop 32: 505-508.

23. Moretti ML, Resende MR, Lazéra MS, Colombo AL, Shikanai-Yasuda MA (2008) [Guidelines in cryptococcosis2008]. Rev Soc Bras Med Trop 41: 524-544.

24. Chen SC, Korman TM, Slavin MA, Marriott D, Byth K, Bak N, Currie BJ, Hajkowicz K, Heath CH, Kidd S, McBride WJ, Meyer W, Murray R, Playford EG, Sorrell TC; Australia and New Zealand Mycoses Interest Group (ANZMIG) Cryptococcus Study (2013) Antifungal therapy and management of complications of cryptococcosis due to Cryptococcus gattii. Clin Infect Dis 57: 543-51.5

25. Aoki $F H$, Imai $T$, Tanaka $R$, Mikami $Y$, Taguchi $H$, Nishimura NF, Nishimura K, Miyaji M, Schreiber AZ, Branchini ML (1999) New PCR primer pairs specific for Cryptococcus neoformans serotype A or B prepared on the basis of random amplified polymorphic DNA fingerprint pattern analyses. J Clin Microbiol 37: 315-20.

26. Horta JA, Staats CC, Casali AK, RibeiroAM, Schrank IS,Schrank A, Vainstein MH (2002) Epidemiological aspects of clinical and environmental Cryptococcus neoformans isolates in the Brazilian state Rio Grande do Sul. Med Mycol, 40: $565-571$.

27. Del Poeta M, Toffaletti DL, Rude TH, Dykstra CC, Heitman J, Perfect JR (1999) Topoisomerase I is essential in Cryptococcus neoformans: role In pathobiology and as an antifungal target Genetics 152: 167-78.

28. Meyer W, Castañeda A, Jackson S, Huynh M, Castañeda E, Group I.C.S (2003) Molecular typing of IberoAmerican Cryptococcus neoformans isolates. Emerg Infect Dis 9: 189195.

29. Clinical and Laboratory Standards Institute (2008) Reference method for broth dilution antifungal susceptibility testing of yeasts, 3rd ed. CLSI document M27-A3. Clinical and Laboratory Standards Institute, Wayne, PA.
30. Nguyen MH, Yu CY (1998) In vitro comparative efficacy of voriconazole and itraconazole against fluconazole susceptible and resistant Cryptococcus neoformans isolates. Antimicrobial Agents Chemother 42: 471-472.

31. Lozano-Chiu MVL, Paetznick MA, Gannoum, Rex JH (1998) Detection of resistance to amphotericin B among Cryptococcus neoformans clinical isolates: performances of three different media assessed by using E-test and National Committee for Clinical Laboratory Standards M27-A methodologycs. J Clin Microbiol 36: 2817-2822.

32. De Bedout C, Ordóñez N, Gómez BL, Rodríguez MC, Restrepo A, Castañeda E (1999) In vitro antifungal susceptibility of clinical isolates of Cryptococcus neoformans var. neoformans and $C$. neoformans var. gattii. Rev Iberoam Micol 16: 36-39.

33. Vanden Bossche H, Dromer F, Improvisi I, Lozano-Chiu M, Rex JH, Sanglard D (1998) Antifungal drug resistance in pathogenic fungi. Med Mycol 36(1):119-128.

34. Meyer W and Trilles L (2010) Genotyping of the Cryptococcus neoformans/Cryptococcus gattii Species Complex. Australian Biochemist 41:12-15.

35. Springer DJ and Chaturvedi V (2010) Projecting Global Occurrence of Cryptococcus gattii. Emerging Infectious Diseases 16: 14-20.

36. Trilles L, Lazéra MS, Wanke B, Oliveira RV, Barbosa GG, Nishikawa MM, Morales BP, Meyer W (2008) Regional pattern of the molecular types of Cryptococcus neoformans and Cryptococcus gattii in Brazil. Mem Inst Oswaldo Cruz 3: 455-462.

37. Silva PR, Rabelo RAS, Terra APS, Teixeira DNS (2008) Suscetibilidade a antifúngicos de variedades de Cryptococcus neoformans isoladas de pacientes em hospital universitário. Rev Soc Bras Med Trop 41: 158-162.

38. Kidd SE, Hagen F, Tscharke RL, Huynh M, Bartlett KH, Fyfe M, MacDougall L, Boekhout T, Kwon-Chung KJ, Meyer W (2004) A rare genotype of Cryptococcus gattii caused the cryptococcosis outbreak on Vancouver Island (British Columbia, Canada). Proc Natl Acad Sci USA 101:1725817263.

39. Byrnes EJ, Li W, Lewit Y, Ma H, Voelz K, Ren P, Carter DA, Chaturvedi V, Bildfell RJ, Bildfell RJ, May RC, Heitman J (2010) Emergence and pathogenicity of highly virulent Cryptococcus gattii genotypes in the northwest United States. PLoS Pathog 6: e1000850.

40. Hagen $\mathrm{F}$, Colom MF, Swinne D, Tintelnot $\mathrm{K}$, Iatta $\mathrm{R}$, Montagna MT, Torres-Rodriguez JM, Cogliati M, Velegraki A, Burggraaf A, Kamermans A, Sweere JM, Meis JF, Klaassen CH, Boekhout T (2012) Autochthonous and dormant Cryptococcus gattii infections in Europe. Emerg Infect Dis. 18: 1618-24.

41. Anzai MC,Takarara DT, Simi W B, Wanke B, Lazera M S, Trillles L, Nakasato L, Dutra V, de Paula DA, Hahn, RC (2013) Cryptococcus gattii in a Plathymenia reticulate reticulate hollow in a Cuiabá, Mato Grosso. Brazil. Mycoses. In press.

42. Martins LMS, Wanke B, Lazéra MS, Trilles L, Barbosa GG, Macedo RCL, Cavalcanti MAS, Eulálio KD, Castro JAF, Silva AS, Nascimento FF, Gouveia VA, Monte SJH (2008) Genotypes of Cryptococcus neoformans and Cryptococcus gattii as agents of endemic cryptococcosis in Teresina, Piauí (northeastern Brazil). Mem Inst Oswaldo Cruz 106: 725-730.

43. Datta K, Jain N, Sethi S, Rattan A, Casadevall A, Banerjee U (2003) Fluconazole and itraconazole susceptibility of clinical 
isolates of Cryptococcus neoformans at a tertiary care centre in India: a need for care. J Antimicrob Chemother 52: 683-68.

44. Tay ST, Tanty Haryanty T, Ng KP, Rohani MY, Hamimah H (2006) In vitro susceptibilities of Malaysian clinical isolates of Cryptococcus neoformans var. grubii and Cryptococcus gattii to five antifungal drugs. Mycoses 49: 324-30.

45. Lia M, Liaob Y, Chena M, Pana W, Weng L (2012) Antifungal susceptibilities of Cryptococcus species complex isolates from AIDS and non-AIDS patients in Southeast China. Braz J Infect Dis 16: 175-179.

46. Sar B, Monchy D, Vann M, Keo C, Sarthou JL, Buisson Y (2004) Increasing in vitro resistance to fluconazole in Cryptococcus neoformans Cambodian isolates: April 2000 to March 2002. J Antimicrob Chemother 54: 563-565.

47. Soares BM, Santos DA, Kohler LM, César GC, Carvalho IR, Martins MA, Cisalpin OS (2008) Cerebral infection caused by Cryptococcus gattii: a case report and antifungal susceptibility testing. Rev Iberoam Micol 25: 242-245.

48. Hagen F, Illnait-Zaragozi MT, Bartlett KH, Swinne D,Geertsen E, Klaassen CHW, Boekhout T, Meis JF (2010) In Vitro Antifungal Susceptibilities and Amplified Fragment Length Polymorphism Genotyping of a Worldwide Collection of 350 Clinical, Veterinary, and Environmental Cryptococcus gattii Isolates. Antimicrob Agents Chemother 54: 51395145.

49. Chong HS, Dagg R, Malik R, Chen S, Carter D (2010) In Vitro Susceptibility of the Yeast Pathogen Cryptococcus to Fluconazole and Other Azoles Varies with Molecular Genotype. J Clin Microbiol 48: 4115-4120.

50. Iqbal N, DeBess EE, Wohrle R, Sun B, Nett RJ, Ahlquist AM, Chiller T, Lockhart SR for the Cryptococcus gattii Public Health Working Group (2010) Correlation of Genotype and In Vitro Susceptibilities of Cryptococcus gattii
Strains from the Pacific Northwest of the United States. J Clin Microbiol 48: 539-544.

51. Thompson GR, Wiederhold NP, Fothergill AW, Vallor AC, Wickes BL, Patterson TF (2009) Antifungal Susceptibilities among Different Serotypes of Cryptococcus gattii and Cryptococcus neoformans. Antimicrob Agent Chemother 53: 309-311.

52. Espinel-Ingroff A, Aller AI, Canton E, Castañón-Olivares LR, Chowdhary A, Cordoba S, Cuenca-Estrella M, Fothergill A, Fuller J, Govender N, Hagen F, Illnait-Zaragozi MT, Johnson E, Kidd S, Lass-Flörl C, Lockhart SR, Martins MA, Meis JF, Melhem MS, Ostrosky-Zeichner L, Pelaez T, Pfaller MA, Schell WA, St-Germain G, Trilles L, Turnidge J (2012) Cryptococcus neoformans-Cryptococcus gattii species complex: an international study of wild-type susceptibility endpoint distributions and epidemiological cutoff values for fluconazole, itraconazole, posaconazole, and voriconazole. Antimicrob Agents Chemother. 56: 5898-5906.

53. Souza LKH, Fernandes OFL, Kobayashi CCBA, Passos XS, Costa CR, Lemos JA, Souza-Júnior AH, Silva MRR (2005) Antifungal susceptibilities of clinical and environmental isolates of Cryptococcus neoformans in Goiânia City, Goiás, Brazil. Rev Inst Med Trop S Paulo 47: 253-256.

\section{Corresponding author}

Dra. Rosane Christine Hahn

Faculdade de Medicina-UFMT: Av. Fernando Corrêa da Costa

2367, Boa Esperança 78060-900, Cuiabá, MT, Brazil

Phone +55 6536158809

Email: rchahn@terra.com.br

Conflict of interests: No conflict of interests is declared. 